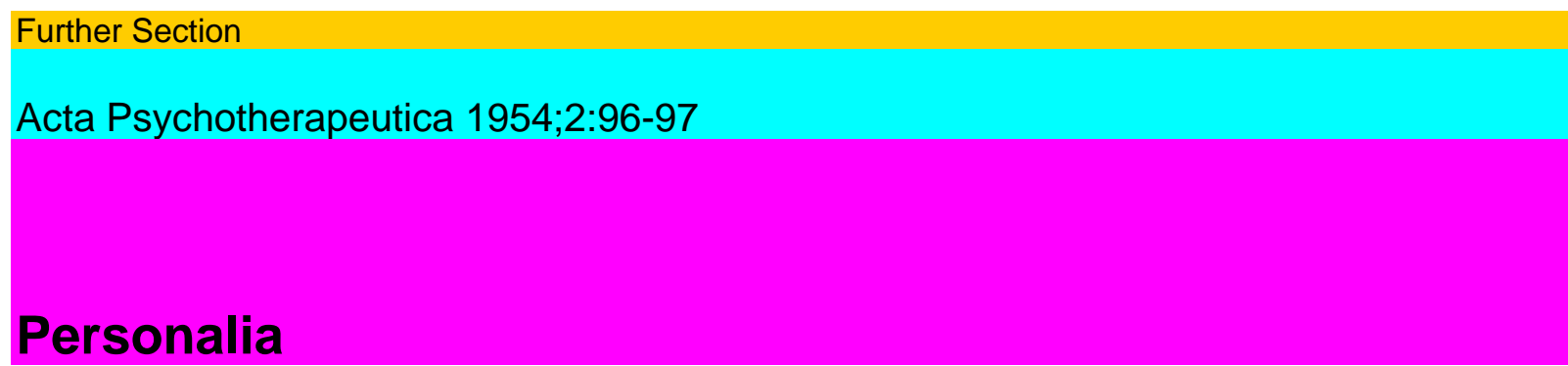

J. H. Schultz zuтn 70. Geburtstag.

Am 20. Juni 1954 ist Johann Heinrich Schultz siebzig Jahre alt geworden. Wer den „J.H.” in seiner jugendlichen Frische und Heiterkeit kennt, wird dies kaum glauben können. Das Lebenswerk von J. H. Schultz beschreiben, hieße die Entwicklung der modernen Psychotherapie aufrollen. Seine vielen Veröffent-lichungen bedeuten ebenso viele wertvolle Belehrungen über die aktuellen Fragen der Psychotherapie; sie zeichnen sich immer wieder aus durch ihre Besonnenheit, Reife, Klarheit, Gründlichkeit und Originalität. Und dasselbe gilt für seine Vorträge, die durch ihren großen Humor geradezu einzigartig sind. Durch die Entwicklung und Weitergestaltung der überaus wertvollen Methode des autogenen Trainings hat sich J. H. Schultz ein monumentum aere perennius erworben. Die Redaktion gratuliert ihrem hochgeschätzten Mitarbeiter und Freund zum 70. Geburtstag recht herzlich!

\title{
B. STOKVIS
}

Ernst Speer 65 Jahre alt.

Ebenfalls am 20. Juni 1954 ist der bekannte Vorkämpfer der Psychotherapie Ernst Speer 65 Jahre alt geworden. In dem Kreis der Leser unserer Zeitschrift diirfte es überflüssig sein, auf die großen Verdienste dieses vielbegabten Forschers näher einzugehen. Seine Sehriften über die von ihm inaugurierte Kontaktpsychologie gehören zum Besten, was die deutschsprachige Literatur zu bieten hat; aus ihnen sprechen nicht nur seine Gelehrsamkeit und blendende didaktische Begabung, sondern auch seine tieffühlende Menschlichkeit und die Güte des reifen Arztes. Als Leiter der ausgezeichneten Lindauer Psychotherapie-wochen hat Prof. Speer sich als erstklassiger Organisator erwiesen. Die Redaktion entbietet dem verehrten Mitarbeiter und Freund, Prof. Speer, zu seinem 65. Geburtstag ihre besten Wünsche.

B. STOKVIS 